\title{
Implementasi Kebijakan Kurikulum Kebaharian di SMA Hang Tuah 5 Sidoarjo
}

\author{
Sugiarto $^{1}$, A. Subianto ${ }^{2}$, Nuhman ${ }^{3}$ \\ 1,2,3 Universitas Hang Tuah Surabaya \\ Jl. Rahman Hakim No.150 Surabaya 60111 \\ ${ }^{*}$ Correspondence email: sugibond72@yahoo.com
}

\begin{abstract}
Abstrak. Pemerintah daerah Sidoarjo dalam memanfaatkan potensi daerahnya, telah melakukan berbagai upaya untuk meningkatkan tingkat kesejahteraan masyarakat. Potensi daerah Sidoarjo yang sangat signifikan salah satunya adalah di bidang kelautan. Adanya hasil laut tersebut, harus diimbangi dengan penyiapan sumber daya manusia di bidang kelautan, salah satunya melalui pendidikan dengan dikeluarkannya peraturan Bupati Sidoarjo Nomor 16 Tahun 2012 tentang pelaksanaan kurikulum muatan lokal. Kebijakan ini, diharapkan dapat mencakup bidang kebaharian yang sesuai dengan potensi daerah Sidoarjo dan diimplementasikan pada lembaga pendidikan tingkat SMA. Tujuan penelitian ini adalah untuk mengetahui penerapan kebijakan Bupati Sidoarjo tentang kurikulum muatan lokal kebaharian, dan menganalisis faktor-faktor yang menghambat dan menunjang. Penelitian ini merupakan penelitian kualitatif, dengan teknik pengumpulan data melalui observasi,wawancara dan dokumentasi. Sedangkan teknik analisa data meliputi reduksi data, penyajian data dan kesimpulan. Hasil penelitian ini menunjukkan bahwa kebijakan kurikulum muatan lokal kebaharian belum dapat diimplementasikan sepenuhnya di lembaga pendidikan tingkat SMA. Namun demikian upaya-upaya yang telah dilakukan sekolah dalam memenuhi kemampuan minimal sesuai peraturan Bupati Sidoarjo dapat tercapai. Penelitian ini diharapkan dapat memeberikan kontribusi pada lembaga pendidikan berupa dirumuskannya kebijakan peningkatan pendidikan para tenaga pendidik pada jenjang yang lebih tinggi di bidang kebaharian, perekrutan tenaga pendidikan dari Sarjana lulusan kebaharian atau sejenisnya dan standarisasi fasilitas pendidikan kebaharian.
\end{abstract}

Kata kunci: Kebijakan; Kurikulum; Lokal; Kebaharian

\begin{abstract}
The Sidoarjo regional government in exploiting the potential of its area, has made various efforts to improve the level of community welfare. One of the significant potential of the Sidoarjo area is in the marine sector. The existence of these marine products, must be balanced with the preparation of human resources in the field of maritime affairs, one of which is through education with the issuance of Sidoarjo Regent's Regulation No. 16 of 2012 concerning the implementation of local content curriculum. This policy is expected to be able to cover the field of maritime in accordance with the potential of the Sidoarjo region and be implemented in high school level educational institutions. The purpose of this study was to determine the application of the Sidoarjo Regent's policy on the curriculum of local maritime and to analyze the factors that hamper and support it. This research is a qualitative research, with data collection techniques through observation, interviews and documentation. While data analysis techniques include data reduction, data presentation and conclusions. The results of this study indicate that the curriculum policies on local maritime have not yet been fully implemented in high school level educational institutions. However, efforts that have been made by schools to meet the minimum capability according to the Sidoarjo Regent's regulations can be achieved. This research is expected to be able to contribute to educational institutions in the form of the formulation of policies to improve the education of educators at higher levels in the field of maritime affairs, recruitment of education personnel from graduates of maritime graduates or the like and standardization of marine education facilities.
\end{abstract}

Keywords: Curriculum; Local; Maritime; Policy

\section{PENDAHULUAN}

Potensi Kabupaten Sidoarjo sangat signifikan di bidang kelautan, hal ini dibuktikan dengan produksi penangkapan ikan laut menurut jenisnya sebagai berikut; ikan dorang 458.850 ton, udang 346.700 ton, udang lain 65.900 ton, kakap 68.800 ton. Sedangkan produksi ikan di tambak menurut jenisnya pada tahun 2015 sebagai berikut; ikan bandeng 33.863.700 ton, udang windu 3.613.000 ton, udang venamei 6.929.600 ton dan nila 13.661.800 ton (BPS Kab Sidoarjo, 2016). Adanya potensi kelautan tersebut, dijadikan dasar bagi pemerintah kabupaten Sidoarjo untuk meningkatkan sumber daya manusia yang ada melalui berbagai program kebijakan, salah satunya adalah di bidang pendidikan dengan dikeluarkannya peraturan Bupati
Sidoarjo Nomor 16 Tahun 2012 tentang pelaksanaan kurikulum muatan lokal (Peraturan Bupati Sidoarjo, 2012). Kebijakan tersebut dinilai masih kurang dapat diimplementasikan pada kurikulum muatan lokal di bidang kebaharian pada tingkat sekolah menengah atas. Hal ini dikarenakan terdapat beberapa kendala antara lain ditinjau dari bidang pembangunan ekonomi, pada sektor kelautan selalu menjadi bidang yang tidak diprioritaskan selama tiga dasawarsa terakhir (M. Arif Zainul Fuad, 2017). Selain itu potensi kelautan masih belum optimal dikelola oleh bangsa Indonesia karena keterbatasan kemampuan sumber daya manusia (Subijanto, 2011). Beberapa hasil penelitian ilmiah terdahulu menunjukkan bahwa dalam pemberdayaan potensi daerah sebagai ikon lokal, terdapat korelasi yang 
positif dengan kurikulum muatan lokal yang diaplikasikan melalui proses belajar mengajar secara inovatif, aktif, kreatif dan implementasi kurikulum muatan lokal tersebut diperlukan strategi pembelajaran (Marliana and Hikmah, 2013). Pada pelaksanaan di lapangan penerapan kurikulum muatan lokal ini menemui berbagai kendala antara lain menyangkut kompetensi para tenaga pendidik, jumlah jam pelajaran, fasiltas yang dimiliki (Zhang, Xiao and Liu, 2017), selain itu diperlukan ketersediaan media belajar yang modern disesuaikan dengan kondisi saat ini (Erdogan and Demirel, 2015). Berdasarkan pada hasil penelitian tersebut, potensi kelautan Sidoarjo yang sangat signifikan ini seharusnya dapat diimplementasikan pada kurikulum muatan lokal kebaharian, sehingga dapat menunjang upaya peningkatan kualitas sumber daya manusia di bidang kebaharian. Namun demikian pada pelaksanaan di lapangan, kurikulum muatan lokal kebaharian pada lembaga pendidikan tingkat SMA belum dapat diterapkan sepenuhnya. Hal ini perlu dilakukan kajian mengapa implementasi kebijakan kurikulum muatan lokal kebaharian belum optimal diterapkan pada lembaga pendidikan tingkat SMA.

\section{METODE}

Penelitian ini merupakan penelitian kualitatif, yakni penelitian yang menghasilkan data secara deskriftif dari sumber informasi yang diamati (Moleong, 2016). Adapun sumber informasi pada penelitian ini melibatkan seluruh para guru mata pelajaran kebaharian di tiap-tiap tingkatan kelas sejumlah 3 orang, kepala sekolah dan wakil kepala sekolah sejumlah 4 orang, staf pengajar sejumlah 3 orang dan para siswa dari kelas $X$ sampai dengan kelas XII sejumlah 50 siswa. Sedangkan teknik pengumpulan data menggunakan langkah-langkah sebagai berikut:

\section{Observasi}

Observasi dalam penelitian ini merupakan pengamatan terhadap segala hal baik orang, lingkungan, kegiatan dan obyek-obyek lainnya serta dilakukan secara tidak langsung.

\section{Wawancara}

Wawancara dilakukan untuk mendapatkan informasi yang mendalam dari nara sumber yang terkait sebagai informan.

\section{Dokumentasi}

Dokumentasi dilakukan dengan mengumpulkan dan mengolah data, dokumen, foto, gambar, audio visual dan film.

\footnotetext{
Analisis data

Reduksi Data

Reduksi data dilakukan dengan menilai dan mengklasifikasikan data primer yang menunjang penelitian.
}

\section{Penyajian Data}

Penyajian data dilakukan setelah data yang dinilai selanjutnya ditampilkan kedalam berbagai jenis tabel, diagram ataupun gambar.

\section{Kesimpulan Data}

Kesimpulan data dilakukan dengan menganalisis data yang selanjutnya disimpulkan.

\section{HASIL DAN PEMBAHASAN}

Hasil dan pembahasan pada penelitian ini menggunakan teori kebijakan Van Metter dan Van Horn meliputi; tujuan dan sasaran, sumber-sumber kebijakan, karakteristik lembaga pelaksana, komunikasi antar organisasi, sikap para pelaksana, dan kondisi lingkungan ekonomi, sosial dan politik (Winarno, 2016). Adapun hasil dan pembahasan dapat dijabarkan sebagai berikut:

\section{Tujuan dan Sasaran Kebijakan}

Parameter tujuan dan sasaran kebijakan meliputi tersusunnya silabus, rencana pelaksanaan pembelajaran (RPP), lembar kerja siswa, lembar penilaian dan pencapaian nilai standar minimum kompetensi siswa pada mata pelajaran kebaharian. Dalam merumuskan materi silabus dan RPP, para guru mata pelajaran kebaharian bekerja sama dan mendapat bimbingan dari narasumber yang berasal dari instansi dan universitas terkait. Sementara itu, hasil nilai rata-rata ujian siswa dapat tercapai melampaui nilai minimal. Hal ini sebagaimana disampaikan oleh ibu Silvi : “.....nilai yang diperoleh siswa...pak..rata-rata mencapai di atas nilai kriteria ketuntasan minimal...artinya ini telah melampaui nilai standar yang telah ditentukan...”.

Tabel 1. Daftar hasil ujian

\begin{tabular}{llllrr}
\hline No & \multicolumn{1}{c}{ Nama Guru } & Kelas & Harian & Smt & UTS \\
\hline 1 & Anita Susetyowati, S.Pd & XII & 88,27 & 89,82 & 89,73 \\
2 & Silvia Sofyanita, S.Pd & XI & 89,23 & 91,33 & 90,02 \\
3 & Nur Hadi, S.T & X & 88,19 & 89,07 & 89,21 \\
\hline *) Sumber data wakil kepala & sekolah & bidang kurikulum tahun \\
2018 diolah kembali & & & &
\end{tabular}

\section{Sumber-Sumber Kebijakan}

a. Tenaga pendidik mata pelajaran kebaharian diambil dari tenaga pendidik yang tidak memiliki keahlian di bidang kebaharian, namun demikian telah dilaksanakan kebijakan berupa program peningkatan kompetensi guru mata kuliah kebaharian. Hal ini sebagaimana disampaikan pada wawancara dengan kepala sekolah ibu Erni: “...yaa ini gimana yaa karena kami tidak mempunyai guru lulusan sarjana kebaharian dan di perguruan tinggi kayaknya belum ada juga lulusan sarjana kebaharian..." 
Tabel 2. Daftar nama tenaga pendidik

\begin{tabular}{clll}
\hline No & \multicolumn{1}{c}{ Nama } & \multicolumn{1}{c}{$\begin{array}{c}\text { Mapel } \\
\text { Pokok }\end{array}$} & $\begin{array}{c}\text { Mapel } \\
\text { Tambahan }\end{array}$ \\
\hline 1 & Anita Susetyowati, S.Pd & Sejarah & Kebaharian \\
2 & Silvia Sofyanita, S.Pd & Fisika & Kebaharian \\
3 & Nur Hadi, S.T & Komputer & Kebaharian \\
\hline
\end{tabular}

*) Sumber data wakil kepala sekolah bidang kurikulum tahun 2018

b. Siswa yang melaksanakan pendidikan dari tahun ke tahun meningkat. Hal ini dapat dilihat pada tabel berikut :

Tabel 3. Jumlah siswa

\begin{tabular}{lclllc}
\hline No & Tahun & \multicolumn{1}{c}{ Kls X } & Kls XI & Kls XII & Jumlah \\
\hline 1 & $2014-2015$ & 82 & & & 82 \\
2 & $2015-2016$ & 124 & 82 & & 206 \\
3 & $2016-2017$ & 217 & 124 & 81 & 422 \\
4 & $2017-2018$ & 218 & 214 & 126 & 558 \\
5 & $2018-2019$ & 204 & 219 & 211 & 634 \\
\hline
\end{tabular}

*) Sumber data wakil kepala sekolah bidang kesiswaan tahun 2018

c. Staf kependidikan yang mendukung penyelenggaraan pendidikan terdiri dari pegawai tetap yayasan (PTY) dan pegawai tidak tetap (PTT) sebagai berikut:

Tabel 4. Jumlah staf pengajar

\begin{tabular}{llllcccc}
\hline No & Status & L & P & Jml & SLTA & S1 & Jml \\
\hline 1 & PTY & 1 & 3 & 4 & 2 & 2 & 4 \\
2 & PTT & 3 & 6 & 9 & 5 & 4 & 9 \\
\hline
\end{tabular}

*) Sumber data wakil kepala sekolah bidang kesiswaan tahun 2018

d. Fasilitas pendidikan yang dimiliki yang mendukung kegiatan belajar mengajar sebagai berikut :

Tabel 5. Fasilitas pendidikan

\begin{tabular}{llc}
\hline No & Jenis Fasdik & Jumlah \\
\hline 1 & Kelas & 23 \\
2 & Laboratorium & 5 \\
3 & Perpustakaan & 1 \\
4 & Masjid & 1 \\
5 & Lapangan & 1 \\
\hline
\end{tabular}

*) Sumber data wakil kepala sekolah bidang sarana prasarana tahun 2018

\section{Karakteristik Lembaga Pelaksana}

Karakteristik lembaga pelaksana merupakan struktur birokrasi yang menggambarkan pola-pola relasi antar satuan kerja dalam melaksanakan tugas pokok sesuai bidangnya masing-masing. Hasil peneitian ini menunjukkan bahwa pola-pola relasi antara kepala sekolah sebagai leader sangat dominan dalam menjabarkan implementasi kebijakan kurikulum muatan lokal kebaharian sesuai Peraturan Bupati Sidoarjo (Perbub Sidoarjo) kepada para tenaga pendidik, siswa dan staf pendidikan.

\section{Komunikasi antar Organisasi}

Kepala sekolah dalam mengimplementasikan kebijakan Perbub Sidoarjo, menggunakan komunikasi formal melalui proses birokrasi penerbitan surat-surat kepada para pelaksana kebijakan dan komunikasi secara informal melalui kegiatan anjang sana, diskusi dan social gathering dengan para pelaksana kebijakan di lapangan.

\section{Sikap para Pelaksana}

Sikap para pelaksana kebijakan menunjukkan adanya sinergitas antara kepala sekolah dengan para tenaga pendidik yang mampu menjabarkan instruksi, arahan dan bimbingan kepala sekolah berupa tersusunnya RPP, Silabus, lembar kerja siswa, dan evaluasi. Begitu pula antara para tenaga pendidik dengan para siswa yang mampu menunjukkan hasil prestasi akademik mata pelajaran kebaharian mencapai di atas rata-rata minimum serta antusiasme para peserta didik dalam melaksanakan kegiatan ekstrakurikuler yang berkaitan dengan kebaharian.

Tabel 6. Jumlah Peserta Ekstrakurikuler

\begin{tabular}{|c|c|c|c|c|c|}
\hline No & Ekstrakurikuler & $\begin{array}{c}\text { Kls } \\
\text { X }\end{array}$ & $\begin{array}{l}\text { Kls } \\
\text { XI }\end{array}$ & $\begin{array}{l}\text { Kls } \\
\text { XII }\end{array}$ & Ket \\
\hline 1 & $\begin{array}{l}\text { Pramuka } \\
\text { Sakabahari }\end{array}$ & 130 & 94 & & $\begin{array}{l}\text { Kls XII tidak } \\
\text { ikut }\end{array}$ \\
\hline 2 & Paskibra & 25 & 21 & & ekstrakurikuler \\
\hline 3 & Marcing Band & 50 & 30 & & persiapan test \\
\hline 4 & $\begin{array}{l}\text { Olah Raga } \\
\text { Perairan }\end{array}$ & 58 & 40 & & ke PT \\
\hline 5 & Journalistik & 21 & 10 & & \\
\hline 6 & Tari & 15 & 7 & & \\
\hline 7 & Bahasa Asing & 17 & 12 & & \\
\hline
\end{tabular}

*) Sumber data wakil kepala sekolah bidang kesiswaan tahun 2018

\section{Kondisi Sosial dan Ekonomi}

Kondisi sosial masyarakat di sekitar lingkungan sekolah merupakan masyarakat majemuk, terdiri dari berbagai suku dan agama. Beberapa aspek yang mempengaruhi kondisi lingkungan sosial tercermin dari pola hidup masyarakat sekitar, diantaranya pola hidup masyarakat yang perduli terhadap kondisi kesehatan lingkungan. Berdasarkan data BPS Kabupaten Sidoarjo tahun 2018, sarana kesehatan yang ada di Desa/Kelurahan Gelam, terdapat 1 Poliklinik/Balai Pengobatan, 1 Polindes, 1 tempat praktek dokter, 1 tempat praktek bidan, dan 7 posyandu. Kondisi ekonomi masyarakat sekitar juga sangat heterogen, mayoritas didominasi oleh buruh. Pada bidang ekonomi, mata pencaharian masyarakat sekitar didominasi oleh buruh swasta, disusul pegawai negeri, buruh tani, petani dan TNI. Hal ini menunjukkan adanya kemajemukan dan perbedaan tingkat pendapatan masyarakat. 
Tabel 7. Jenis pekerjaan

\begin{tabular}{lll}
\hline No & \multicolumn{1}{c}{ Jenis Pekerjaan } & Jumlah \\
\hline 1 & Pegawai Negeri & 59 \\
2 & TNI & 12 \\
3 & Petani & 42 \\
4 & Buruh Tani & 49 \\
5 & Buruh Swasta & 429 \\
\hline
\end{tabular}

*) Sumber BPS Kab. Sidoarjo tahun 2018

\section{Pembahasan \\ Tujuan dan Sasaran Kebijakan}

Perumusan materi kurikulum kebaharian oleh para tenaga pendidik mata pelajaran kebaharian masih menjadi hambatan, hal ini disebabkan para tenaga pendidik mata pelajaran kebaharian tidak memiliki kompetensi di bidang kebaharian dan tugas mengajar pada mata pelajaran kebaharian merupakan tugas tambahan, selain itu sekolah tidak memiliki tenaga pendidik yang berasal dari lulusan sarjana kebaharian. Kebijakan yang telah dilakukan oleh kepala sekolah diantaranya memberikan penugasan kepada para tenaga pendidik mata pelajaran kebaharian untuk mengikuti kursus, pelatihan, seminar, work shop kebaharian. Selain itu kepala sekolah mengadakan kerja sama dengan berbagai instansi yang terkait di bidang kebaharian, antara lain dengan mendatangkan para nara sumber untuk memberikan kursus singkat, membentuk kelompok diskusi guru mata pelajaran kebaharian, memberikan buku referensi materi kebaharian dan penyusunan materi kebaharian.

\section{Komunikasi antar Organisasi}

Dalam menjabarkan kebijakan Perbub Sidoarjo tentang kurikulum muatan lokal, kepala sekolah telah berupaya memberikan pemahaman, arahan dan bimbingan kepada para pelaksana kebijakan di sekolah dengan membangun komunikasi yang efektif dalam meningkatkan kompetensi para guru dan pencapaian kompetensi minimum siswa pada mata pelajaran kebaharian. Bentuk komunikasi dilaksanakan dengan menjalin kerja sama antar instansi dan menjalin suatu hubungan komunikasi internal dengan para guru, sehingga informasi atau pesan yang disampaikan dapat dimengerti dan dijabarkan oleh para guru dalam mengimplementasikan kebijakan yang telah ditetapkan. Komunikasi yang terlaksana dapat bersifat formal dalam bentuk birokrasi administrasi berupa surat penugasan, instruksi, keputusan dan sebagainya, dan dapat bersifat informal dalam bentuk anjang sana, kunjungan, dan sebagainya.

\section{Sikap para Pelaksana}

Sikap para guru dalam mengimplementasikan kebijakan yang telah ditetapkan, menunjukkan sikap kooperatif dan sinergi, hal ini disebabkan adanya keinginan yang kuat dari para pelaksana di lapangan dan kemudahan-kemudahan yang diberikan kepala sekolah, sehingga tujuan dan sasaran kebijakan dapat tercapai.

\section{SIMPULAN}

Kesimpulan dari penelitian ini adalah bahwa implementasi kebijakan kurikulum muatan lokal belum dapat terlaksana sepenuhnya. Hal ini disebabkan faktorfaktor tenaga pendidik yang mengajar tidak sesuai dengan bidangnya, dan fasilitas pendidikan terbatas, namun demikian kepala sekolah telah melakukan upayaupaya untuk meningkatkan kompetensi dan kinerja dari para guru yang mengajar pada mata pelajaran kebaharian sehingga hasilnya dapat melampaui kompetensi minimum sebagaimana yang disyaratkan pada Perbub Sidoarjo Nomor 16. Berdasarkan pada hasil penelitian ini, diharapkan dapat memberikan kontribusi kepada lembaga pendidikan agar dapat merumuskan kebijakan peningkatan pendidikan para tenaga pendidik pada jenjang yang lebih tinggi di bidang kebaharian, perekrutan tenaga pendidikan dari Sarjana lulusan kebaharian atau sejenisnya dan standarisasi fasilitas pendidikan kebaharian.

\section{DAFTAR PUSTAKA}

BPS Kab Sidoarjo (2016) Sidoarjo dalam Angka.

Erdogan, O. and Demirel, E. (2015) 'New technologies in maritime education and training, Turkish experiment', Turkish Online Journal of Educational Technology, 2015(6), pp. 432-439. doi: 10.13189/ujer.2017.050606.

M. Arif Zainul Fuad, M. M. E. (2017) 'PENGENALAN BIDANG KEMARITIMAN SEJAK USIA DINI MELALUI PEMBELAJARAN TEMATIK KELAUTAN PADA SISWA TAMAN KANAK KANAK', Pendidikan Geografi, pp. 93-104.

Marliana and Hikmah, N. (2013) 'Pendidikan Berbasis Muatan Lokal sebagai Sub Komponen Kurikulum', Dinamika Ilmu, 13(1), pp. 105-119.

Moleong, L. J. (2016) Metode Penelitian Kualitatif. Edisi Revi. Edited by P. R. Rosdakarya. Bandung.

Peraturan Bupati Sidoarjo (2012) Peraturan Bupati sidoarjo.

Subijanto (2011) 'Potensi Kekayaan Alam Kelautan Mendukung Kebijakan Kemdiknas dalam Pengembangan SMK pada Era Otonomi Daerah', Jurnal Pendidikan dan Kebudayaan, 17(5), p. 576. doi: 10.24832/jpnk.v17i5.50.

Winarno (2016) Kebijakan Publik Era Globalisasi. Yogyakarta: Center of Academic Publishing Service (CAPS).

Zhang, W., Xiao, Z. and Liu, J. (2017) 'A Study on Curriculum of Practical Teaching in Nautical Science', Journal of Residuals Science \& Technology, 13(8), pp. 8-11. doi: 10.12783/issn.1544-8053/13/8/230. 